\title{
Cloud computing experience in state healthcare organisations of Sri Lanka
}

\author{
M.G.Y. Piyasena ${ }^{1 *}$, R. Hewapathirana ${ }^{2}$ \\ 1 Postgraduate Institute of Medicine, University of Colombo, Sri Lanka \\ 2 Faculty of Medicine, University of Colombo - Sri Lanka \\ *gayanyp@gmail.com \\ https://orcid.org/0000-0001-6281-1165 \\ ABSTRACT
}

\begin{abstract}
Introduction: Cloud computing has the potential to restructure the way enterprises acquire, utilize and manage their requirements of computing resources efficiently and cost-effectively. This is true in health care organization in both the private and state sectors. However, health care service providers are traditionally considered to be slow technology adopters. For this cautious approach of slow adoption, there are numerous valid and obvious reasons i.e. security of patient data, cost of change, new technology not a primary focus. Therefore, this study carried out to find user concerns of cloud computing within the state health sector of Sri Lanka.
\end{abstract}

Methods: A qualitative research method used. Non-probabilistic sampling technique was used as cloud computing is a new concept and awareness of cloud computing technologies still low even among ICT related staff.

Results: Seven interviews carried out with those who were involved in health IT work in state health care organizations. The thematic areas appearing in cloud computing were; lack of knowledge in cloud computing technology, security, legal and privacy issues, political issues, computer misuse, disaster, theft of intellectual property, abuse of access privileges, data loss or damage and financial issues such as billing model.

Conclusions: In the Sri Lankan healthcare context, cloud computing adoption has not yet started widely. The attitude towards cloud computing is influenced by the security risk and privacy concerns where a lack of policy and legislation were considered major contributing factors. Vendor lock is not a major concern among users as users were not exposed to change in cloud providers. The most preferable cloud service model is a "platform as a service" and most preferable cloud deploying model is "a hybrid cloud". However, the cost of the cloud is not a major barrier and the lack of knowledge among key actors on different modalities of cloud computing is a barrier to its adoption. Hence such barriers should be addressed appropriately to succeed in cloud service adoption for better digital health in the country. Furthermore, cloud computing should be considered strongly in digital health strategy and blueprint of the country.

Keywords: Cloud computing, digital health, cloud adoption, healthcare organization, state healthcare sector 